\title{
SEEC: An area approach to education in emergency departments
}

\author{
Rebecca J. Leon, RN, DipAppSci(Nurs), BN, GradCertEmerg, MHSc(Nurs) ${ }^{a, *}$, \\ Jenny K. Morris, RN, GradCertAcuteCare, MCP ${ }^{\mathrm{b}}$
}

\author{
a The College of Nursing, Burwood, N.S.W., Australia \\ ${ }^{\mathrm{b}}$ Emergency department, Liverpool Hospital, Sydney South West Area Health Service, N.S.W., Australia ${ }^{1}$
}

Received 31 August 2007; received in revised form 19 October 2007; accepted 28 October 2007

\author{
KEYWORDS \\ Emergency nursing; \\ Education; \\ Networking; \\ Career path; \\ Clinical education
}

\begin{abstract}
Summary Providing education to nursing staff in a meaningful, timely, standardised and coordinated manner is a challenge for managers and educators of most emergency departments. The pressures of workload and diminished personnel resources have made providing education increasingly difficult. Education programs can become inequitable, spasmodic, interrupted, and have varying standards. In an area health service in Sydney's South West, a coordinated approach to address the development, coordination, delivery and evaluation of education in the six emergency departments was developed. This education approach began in the late 1990s when the Nurse educator at the major referral hospital brought together educational representatives (clinical nurse educator or clinical nurse specialist) from each of the six emergency departments. This group became known as South Western Sydney Area Health Service Emergency Educators Committee (SEEC). This group has continued to grow and develop and is now well recognised across the area health service as the group responsible for managing emergency department education.

(c) 2007 College of Emergency Nursing Australasia Ltd. Published by Elsevier Ltd. All rights reserved.
\end{abstract}

\section{Introduction}

Providing education to nursing staff in a meaningful, timely, standardised and coordinated manner is a challenge for

\footnotetext{
* Corresponding author at: 202 Stoney Creek Road, Bexley, N.S.W. 2207, Australia. Tel.: +61295548352.

E-mail address: leontribe@optusnet.com.au (R.J. Leon).

1 Formerly South Western Sydney Area Health Service, consisting of Bankstown, Bowral, Camden, Campbelltown, Fairfield, Liverpool hospitals.
}

managers and educators of most emergency departments (EDs). The pressures of workload and diminished personnel resources have made providing education increasingly difficult. As a result education programs can be spasmodic and experience significant interruptions.

In a Sydney Area Health Service (AHS) it was identified that education programs were of varying standards and inequitable. The AHS included six EDs; one level six hospital, two level five and one level four metropolitan and two rural hospitals. The varying size and level of the hospital determined the educational resources available. These resources included one nurse educator (NE) and one clini- 
cal nurse educator (CNE), at the level six hospital and one CNE at each of the level five hospitals. The NE at the level six hospital identified an opportunity to coordinate education across the AHS and to provide a forum where senior clinicians could network and support each other and work towards a standardised approach to education.

Through a consultative process across the EDs it was identified that there were areas of repetition that could be reduced through sharing and the development of a coordinated approach. Repetition included staff having to be reaccredited for clinical skills when they transferred between the departments and educators' replicating educational resources such as databases, lectures and programs.

\section{The role of South Western Sydney Area Health Service Emergency Educators Committee (SEEC)}

SEEC commenced in the late 1990s and included clinical educators, clinical nurse specialists (CNSs) and senior registered nurses from each of the six emergency departments. The group received the full support of management from all hospitals. The rural emergency departments were especially supportive because of their limited resources.

The purpose of SEEC was to develop a coordinated approach to education in the EDs across the AHS, which included the development and implementation of programs, and the ability to share education packages/resources/lectures and ideas.

The objectives were to:

1. Develop education programs and packages at an area level that could be delivered either at an area level or by each ED.

2. Provide a forum to debrief and troubleshoot issues by all those responsible for nursing education.

3. Provide education evenings on a quarterly basis.

4. Review and provide advice on the education impact of new initiatives within South Western Sydney Area Health Service (SWSAHS).

5. Ensure that any education programs and resources were transferable across SWSAHS.

One of the initial projects was to identify and review the education programs that were currently being held, the gaps in education and the development of a career path for registered nurses within the ED.

\section{Review of the literature}

A literature search using the terms 'education', 'emergency nursing', 'education programs', 'clinical education' and 'career pathway' was conducted. Australian literature provided very little in the way of coordinated education programs across a number of hospitals, nor a career structure to provide direction. There were many examples of specific programs within individual hospitals and departments.

\section{Marketing}

The success of the committee depended on the support of the key stakeholders. The managers of the respective EDs were supportive and allowed the respective staff to travel to and host meetings. The group also had the support and recognition from the area nursing education unit. This enabled the group to be recognised as a legitimate group within the AHS, thus enabling it to use educational facilities and resources, especially for the education evenings.

To enhance the profile of the group across the AHS a logo was developed that was used on all of the education materials, flyers, courses and advertising of programs. This was invaluable to the ongoing success of the committee as SEEC became recognised across the AHS as the group responsible for managing ED education.

\section{Achievements}

SEEC has continued success. The committee has maintained its commitment to area wide education and the ability to professionally network and this has been of mutual benefit to hospitals across the AHS. The achievements of SEEC have been the development of an educational support network, career pathway, unification of education and professional evenings.

\section{Education support network}

For the smaller departments having access to qualified staff who were experienced in not only emergency nursing but also education was advantageous to the promotion of an educational pathway. It enabled the sharing of skills, attitudes and knowledge on nursing education to staff with little or no previous educational background.

\section{Career pathway}

One of the biggest achievements was the development of a career pathway that was transferable across the six EDs in the AHS. Fig. 1 demonstrates the progression of a novice emergency nurse through to an advanced senior clinician.

Benner's novice to expert model provided a framework for identifying, defining and describing the clinical nursing practice that was required at each step of the career pathway. In keeping with Benner's ethos "a nurse's clinical knowledge is relevant to the extent to which its manifestation in nursing skills makes a difference in patient care and patient outcomes". 1

It was important to develop education programs that would support the career pathway as well as provide the student the opportunity to integrate and apply the knowledge they learned along the way to their clinical environment. Only then would the nurse be able to progress up the career pathway.

Education programs developed to support this pathway were offered either face-to-face or through self-directed learning packages. It was important to acknowledge that the students were adults who had to juggle shift work and personal and professional commitments. Using the adult 


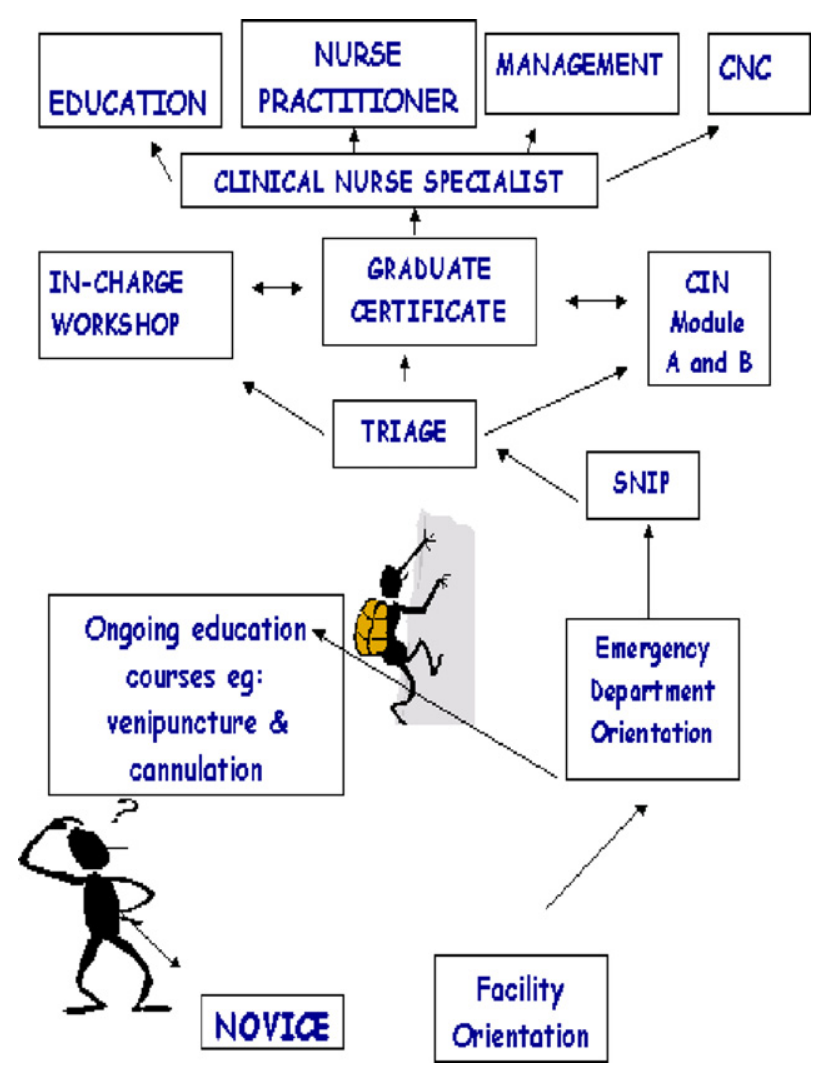

Figure 1 Emergency nurse career pathway.

learning principles there was a combination of teaching and assessment methodologies used. Appropriate written packages were self-directed allowing the students to use their own initiative and take responsibility for their own learning. ${ }^{2}$ The timeline was negotiated with the student, and where appropriate their manager.

\section{Unification of education}

The analysis of education across the AHS revealed inconsistencies in delivery, content and standards. SEEC was important in managing these problems and unified education across the AHS. The first program reviewed and redeveloped was the Triage course. Although the Triage course was financially supported by the AHS, it was conducted at the level six hospital with the content being focused to that hospital. With a commitment from area nursing education the program was reviewed and standardised for process not hospital dependent, to enable the course to be delivered at different sites. Other courses reviewed included the Graduate Certificate in Emergency Nursing and the Specialty Nursing Introductory Program (SNIP). To support the staff in their career pathway a component of the SNIP was written so students could be given advanced standing in the Graduate Certificate in Emergency Nursing.

All programs were developed with a syllabus, lesson plans, standard presentations, workshop outlines, printed materials and access to audiovisual equipment. Where appropriate programs were developed on a competency based assessment to facilitate a standardised level across the AHS. The competencies were written against the standards for the emergency nursing specialist. ${ }^{3}$

To ensure equity across the area each department was allocated two places in each of the courses with the hosting site having the option to fill any vacancies.

\section{Professional evenings}

One of the successful initiatives was the development of quarterly professional evenings that were offered to staff free of charge. SEEC secured sponsorship to provide supper to encourage staff to either attend during their meal break or after their shifts.

The presenters and participants were from the multidisciplinary team that enabled people to share ideas and perspectives about the care of the diverse needs of the emergency patient. These evenings were well supported with attendance varying from 50 to 100 people.

Evaluation of these evenings was conducted through an education evaluation form which asked the participants about their level of satisfaction, relevance to their practice and suggestions or comments/ideas for further evenings. These forms were collated after each evening and the feedback used to direct subsequent evenings.

\section{Further developments}

Since its inception SEEC has continued to grow and evolve. This evolution has included the identification and development of further programs, development of an education calendar and the implementation of a shared network drive to provide an electronic support network for the committee.

The career pathway provided a foundation to meet the education needs of emergency nurses. Since its inception staff members have moved through the pathway and have been successful in applying and working in higher positions. Another benefit is the retention of specialty educated staff who have stayed within emergency nursing and within the area health service. Table 1 provides an indication of positions and numbers.

It was, however, identified there was a need to develop a more comprehensive suite of specialty programs to support the career pathway. This resulted in the development of additional programs which included Paediatric Advanced Resuscitation Study (PARS) Days, disaster management education and airway management. SEEC was given the task by the AHS to develop an education program to support the implementation of the clinical initiatives nurse (CIN), which was a NSW Health initiative.

The need to provide a coordinated approach to the increasing number of programs resulted in the compilation

Table 1 Retention of specialty staff

\begin{tabular}{ll}
\hline Position & Number \\
\hline Management & 6 \\
Clinical nurse educator & 3 \\
Clinical nurse consultant & 2 \\
Nurse practitioner & 3 \\
\hline
\end{tabular}


Table 2 Participant numbers

\begin{tabular}{lll}
\hline Course & Year & Participant numbers \\
\hline Triage & 1999 & 2 courses $\times 23$ participants \\
& 2004 & 3 courses $\times 26$ participants \\
Paediatric Advanced Resuscitation (PARS) & 2003 & 3 courses $\times 16$ participants \\
& 2004 & 6 courses $\times 16$ participants \\
Clinical initiatives nurse (CIN) & 2002 & 2 courses $\times 16$ participants \\
& 2004 & 4 courses $\times 16$ participants \\
\hline
\end{tabular}

of an education calendar. The calendar was developed with consideration of the peaks and troughs in workload and the impact of school holidays on staffing availability.

The expanding functions of SEEC resulted in the need for an area server to enable a more efficient way to manage the communication of SEEC activities. The area server is able to store and share programs, resources, syllabi, lesson plans, presentations, websites, attendance data and evaluation. This reduced the email and need for multiple paper copies. Access is limited to SEEC members.

\section{It is working!}

SEEC is now well recognised and respected across the AHS as the group responsible for managing emergency nursing education. This education network has allowed cross fertilisation between departments enabling part timers and casuals to work in multiple sites. There is greater networking of staff by attendance at the study days, and participant numbers across all programs have steadily increased. Table 2 provides a snap shot of the increase in numbers across three of the courses. Due to database issues more recent numbers were not available at the time of publication.

Feedback from program evaluations have included statements such as:

- 'Great networking.'

- 'Today has provided greater understanding of other sites' issues and their resources.'

- 'Relevant to my practice.'

- 'Good mix of lectures and practical sessions.'

- 'Do not have to jump through multiple hoops to progress career.'

- 'Increased my access to resources available.'

\section{Hints for success}

The authors believe the four key aspects to the success of SEEC are manager's support, coordination, resources and funding.

\section{Manager's support}

From the very beginning the support of the local Nursing Unit Managers was pivotal to launching SEEC. Their ongoing support of the educators to attend meetings and conduct lectures/workshops as well as releasing staff to attend the programs has been invaluable.

\section{Coordination}

Representation from all sites ensured programs met the varying clinical and education needs of the sites and their participants. Strategies such as check lists and the area server supported the coordination of programs. There is no official administrative support; however administrative staff from across the sites and area nursing education are always happy to assist.

\section{Resources}

SEEC enhanced opportunities for members to personally network with clinical experts, pharmaceutical and equipment company representatives. Members also gained greater access to resources that include audiovisual equipment, computer programs, lectures and presenters.

\section{Funding}

The standardisation and restructuring saved money as it minimised the duplication of programs, streamlined staff release and stopped educators writing the same programs. Existing funds were streamlined to support the progression of staff in their emergency career.

\section{Conclusion}

The concept of SEEC has proven to be a sustainable model in the provision of emergency nursing education across a diverse AHS. Despite changes in staff and the original members of the SEEC being no longer involved its structure and principles have remained unchanged. The sound foundation established has allowed SEEC to strengthen and evolve with the changing face and demands of emergency nursing.

\section{Competing Interests}

None declared by the authors.

\section{Funding}

None declared by the authors. 


\section{References}

1. Benner, P, cited in Marriner Tomey, A, Alligood, MA, From novice to expert: excellence and power in clinical nursing practice. Nursing theorists and their work. 4th ed. Missouri: Mosby-Year Book Inc.; 1998. p. 157-69.
2. Boucher, D, cited in O'Shea, KL, Adult learning theory. Staff development nursing secrets. Philadelphia: Hanley and Belfeus, Inc.; 2002. p. 105-13.

3. College of Emergency Nursing Australasia (CENA). Standards for the emergency nursing specialist. 1st ed. College of Emergency Nursing Australiasia; 2003. 